\title{
Vielfältig und komplex
}

Liebe Leserin, lieber Leser,

Entwicklungsdienstleister dürfen sich über mangelnde Chancen nicht beschweren, denn OEMs haben es in diesen Tagen nicht leicht. Sie haben zu kämpfen mit neuen Playern, die auf den Markt drängen, neuen Technologien wie künstlicher Intelligenz oder additiver Fertigung, mit neuen Mobilitätsmodellen wie Carsharing und natürlich auch mit der Elektromobilität und allen ihren Hybridfacetten und Antriebssträngen. Ach ja, und dann war da ja auch noch der Verbrennungsmotor, dessen Weiterentwicklung notwendig ist, da er uns noch lange begleiten wird. Kurz gesagt: Der Entwicklungsaufwand ist in die Höhe und Breite gleichzeitig gewachsen. Und da man einfach gesagt „nicht alles gleichzeitig machen kann“, wie es der SchaefflerEngineering-Chef Rolf Laufs im Interview (ab Seite 18) so prägnant zusammenfasst, ergeben sich für Entwicklungsdienstleister zahlreiche neue Geschäftsfelder, auf denen sie den OEMs helfen können. Vorausgesetzt natürlich, sie haben sich eben in diesen neuen Feldern Know-how erarbeitet oder eingekauft. Gerade das ist aber genau die Schwierigkeit: Marktbewegungen und Technologietrends $\mathrm{zu}$ erkennen, bevor andere es tun, und dann frühzeitig die richtigen (Investitions)Entscheidungen $\mathrm{zu}$ treffen, die einem neue Wachstumschancen eröffnen.

Natürlich bewegen sich die Engineering Partner dabei im gleichen Umfeld wie die OEMs, gekennzeichnet durch größere Vielfalt der Technologien und Antriebsvarianten und daraus folgender Komplexität. Sie müssen sich jedoch einer weiteren Herausforderung stellen: OEMs laden immer mehr Systemverantwortung auf die Entwicklungsdienstleister ab. Das erschwert die Situation zusätzlich, und man muss kein Prophet sein, um zu prognostizieren, dass viele diesen steigenden Anforderungen nicht genügen und durch Verkäufe beziehungsweise Zusammenschlüsse in anderen Unternehmen aufgehen werden. Für die anderen sind die Aussichten glänzend: McKinsey geht von anhaltend hohen Wachstumsraten und einer annähernden Marktverdoppelung bis 2030 aus (siehe Artikel ab Seite 14).

Ich wünsche Ihnen viel Spaß bei der Lektüre dieses ATZextra.

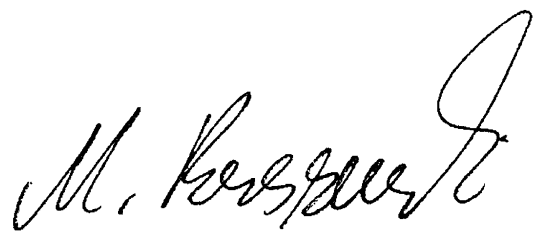

Markus Bereszewski

Leiter Corporate Solutions I Chefredakteur

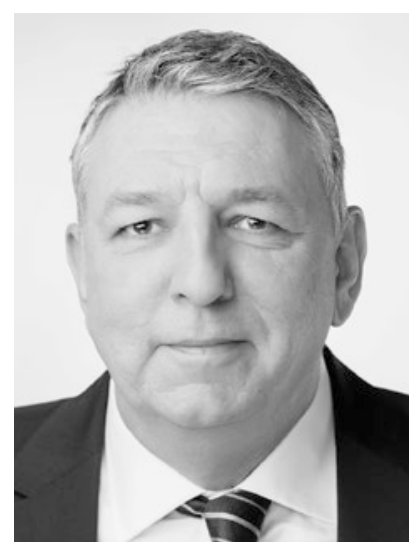

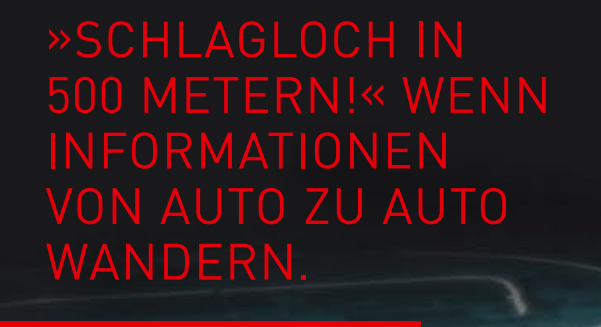

CONNECTIVITY - MIT DEN

AUTOMOTIVE- UND IT-SPEZIALISTEN

VON FERCHAU: WIR SEHEN UNS

IN DER ZUKUNFT!
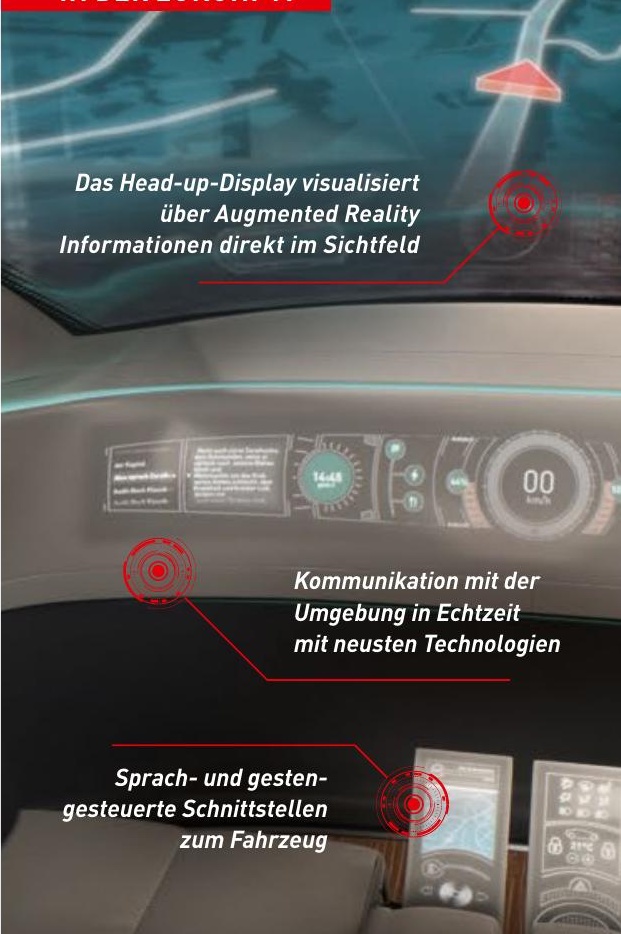

Wir bringen Autos dazu, sich intelligent $z u$ vernetzen und vorausschauend zu handeln. Wir entwickeln Car2X-Software, die automatisch den besten Parkplatz findet und gleich den Restauranttisch reserviert. FERCHAU, Deutschlands Engineering- und IT-Dienstleister Nr. 1, führt Automotive und IT zusammen für die Car Connectivity der Zukunft. Und gern auch für Ihr Unternehmen! Nehmen Sie Kontakt zu uns auf: Gemeinsam kommen wir weiter.

FERCHAU Engineering GmbH

Zentrale

Steinmüllerallee 2

51643 Gummersbach

Fon +4922613006-0

info@ferchau.com 